\title{
Self-similarity in glacier surface characteristics
}

\author{
Neil S. ARNOLD, W. Gareth REES \\ Scott Polar Research Institute, Lensfield Road, University of Cambridge, Cambridge CB2 1ER, England \\ E-mail:nsa12@cus.cam.ac.uk
}

\begin{abstract}
Catchment-wide information on glacier snow-cover depth, surface albedo and surface roughness is important input data for distributed models of glacier energy balance. In this study, we investigate the small-scale ( $\mathrm{mm}$ to $100 \mathrm{~m}$ ) spatial variability in these properties, with a view to better simulating this variability in such models. Data were collected on midre Lovénbreen, a $6 \mathrm{~km}^{2}$ valley glacier in northwest Svalbard. The spatial variability of all three properties was found to be self-similar over the range of scales under investigation. Snow depth and albedo exhibit a correlation length within which measurements were spatially autocorrelated. Late-winter and summer properties of snow depth differed, with smaller depths in summer due to melt, and shorter correlation lengths. Similar correlation lengths for snow depth and surface albedo may suggest that snow-depth variation is an important control on the small-scale spatial variability of glacier surface albedo. For surface roughness, the data highlight a possible problem in energy-balance studies which use microtopographic surveys to calculate aerodynamic roughness, in that the scale of the measurements made affects the calculated roughness value. This suggests that further investigations of the relationships between surface form and aerodynamic roughness of glacier surfaces are needed.
\end{abstract}

\section{INTRODUGTION}

The surface characteristics of ice sheets and glaciers are one of the primary controls on mass balance at both long and short time-scales. Accurate estimates of snow-depth distributions in particular are vital, as snow is the main source of accumulation on ice masses, and plays a key role in determining the surface albedo (e.g. Brock and others, 2000a), which is one of the main controls on the amount of energy either reflected or absorbed by the surface. Given that solar radiation is one of the primary sources of energy for the melting of glaciers and ice sheets, providing $50-80 \%$ of the total energy received by glaciers (Van de Wal and others, 1992; Hock and Holmgren, 1996; Willis and others, 2002), the factors that control the receipt and absorption of solar radiation are of prime importance in determining the energy balance and, hence, mass balance and runoff, from glaciers and ice sheets. Surface topography is also important as, together with solar zenith angle and azimuth, it controls the incidence angle of the solar beam to the surface, and hence the energy receipt. However, the effects of small-scale albedo heterogeneity on radiation receipt and absorption are likely to be important, particularly at high latitudes where solar incidence angles are low and there is 24 hour daylight in the summer. Snow can also have very different surface roughness characteristics from glacier ice (e.g. Munro, 1990; Brock and others, 2000b), and hence patterns of snow cover can also affect the exchange of turbulent energy between the atmosphere and an ice mass.

Models of ice-sheet and glacier mass and energy balance range from simple zero- or one-dimensional statistical relationships between meteorological factors and measured mass balance (e.g. Willis and others, 1993), through degree-day-type approaches (e.g. Laumann and Reeh, 1993; Braithwaite and Zhang, 2000), zero-dimensional (at-a-point) (e.g. Braithwaite and Olesen, 1990; Munro, 1990) and one-dimensional (e.g. Oerlemans, 1993) energybalance studies, to more sophisticated two-dimensional spatially distributed, physically based models (e.g. Munro and Young, 1982; Arnold and others, 1996; Hock and Noetzli, 1997; Brock and others, 2000b). The latter models are used to provide glacier-wide estimates of mass and energy balance, both to better understand spatial controls on these factors (e.g. Brock and others, 2000b) and to provide the water inputs to hydrological models where seasonal and spatial variations in water delivery are a key determinant of the evolution of glacier hydrological systems (e.g. Arnold and others, 1998).

To date, however, spatially distributed mass- or energybalance models of glacier and ice-sheet melt have tended to ignore the role of small-scale $(1-10 \mathrm{~m})$ variability in snow depth and albedo in the absorption of solar radiation (e.g. Oerlemans, 1993; Arnold and others, 1996). Such models typically rely on simple parameterizations to describe the spatial variations in snow depth over a glacier, and their effect on albedo and surface roughness. These parameterizations have typically taken the form of "lapse rate" regression-type relationships between elevation and snow depth measured at relatively few locations, typically along a glacier centre line (e.g. Oerlemans, 1993; Brock and others, 2000b). Coupled with a digital elevation model (DEM) of elevation, these types of relationship allow a simple "digital depth model" of snow distribution to be constructed, which then forms one of the initial boundary conditions in such distributed models.

However, the calculated snow depth from such relation- 


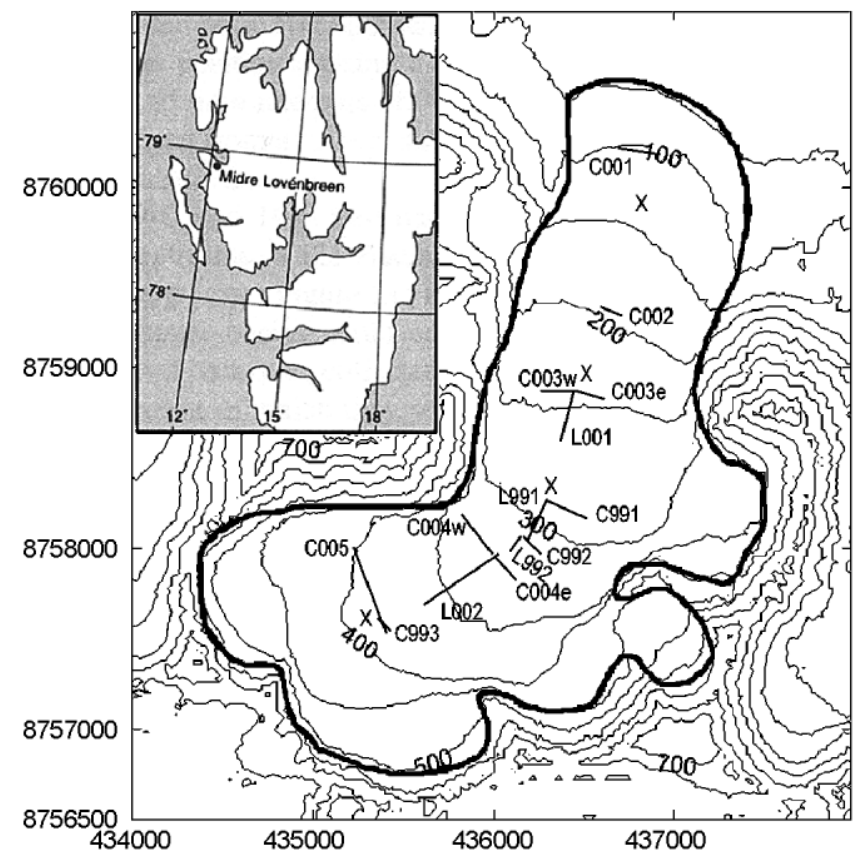

Fig. 1. Location map for midre Lovénbreen, showing locations of snow-depth transects (solid lines) and surface roughness measurement sites (shown as X). Contour interval is $50 \mathrm{~m}$; labels are $m$ a.s.l. The heavy black line denotes the glacier margin. Axes are labelled with Universal Transverse Mercator (UTM) grid coordinates, which have a spatial resolution of $1 \mathrm{~m}$. Inset shows location of midre Lovénbreen within Svalbard. North is to the top of the figure.

ships varies only slowly in space (and time). Detailed field observations of glacier surface characteristics, such as snow depth and albedo, however, show a high degree of spatial variability, which such relationships cannot take into account (Brock and others, 2000a). This spatial variability will affect the total amount of snow water equivalent within the catchment (and hence the mass balance, as well as water inputs to a glacier hydrological system), and, given the dependence of albedo and surface roughness on the presence or absence of snow, will also affect the spatial distribution of melt. As the melt season progresses, field-based and remote-sensing studies show that the transient snowline retreats up-glacier as a zone of patchy snow cover, rather than the sharply delimited "snowline" generated by topographically controlled snow distributions used in distributed models (e.g. Knap and others, 1999). This mix of ice and snow surfaces in real situations is likely to have important implications for the albedo, energy balance and melt near the transient snowline, which current models cannot account for.

Whilst some of the physical factors that control snow albedo at any given location on a glacier surface, such as effective grain-size and liquid water content, are quite well understood (e.g. Wiscombe and Warren, 1980), they are difficult to incorporate into energy-balance studies at the glacier-wide scale. At this scale, spatial variations in albedo have to be prescribed or parameterized. In simple regression or degree-day models, no explicit values are used; rather, different regression or degree-day coefficients are employed for ice, firn and snow, which implicitly account for their different surface properties (e.g. Braithwaite and Zhang, 2000). In more physically based, distributed models, some assume a fixed albedo for the different surface facies (e.g. Escher-Vetter, 1985; Hock and Noetzli, 1997) or use empirical parameterizations relating albedo to snow depth, snow age or various meteorological parameters (e.g. Oerlemans, 1993; Arnold and others, 1996; Brock and others, $2000 \mathrm{~b}$ ). Treatment of surface roughness is even more problematic, as few effective empirical relationships between measured roughness and snow properties or meteorological variables have been made. Studies have typically used constant roughness values for the different facies (e.g. Munro, 1990), or even Gaussian distributions around the measured mean (e.g. Brock and others, 2000b).

This study aims to improve on the relationships used to calculate distributed snow depth, albedo and surface roughness in physically based models by investigating the spatial scales of variation in glacier surface characteristics. Given the very complex physical processes controlling the distribution and redistribution of falling snow in mountainous catchments, and the complex factors controlling snow and ice albedo and roughness, this paper takes a different approach by aiming to understand the statistical properties of snow depth, albedo and roughness distributions, with the ultimate aim of simulating their spatial characteristics statistically, rather than physically, using simple field measurements. The main focus of analysis here is the scales of variation in the spatial distribution of snow depth, in order to determine any self-similarity (or fractal characteristics) within this variation. Knowledge of this should allow the small-scale spatial variability of glacier surface properties to be effectively simulated, using similar techniques to those which have been used to simulate other non-uniform meteorological or hydrological processes, such as snow cover over vegetated landscapes (e.g. Shook and Gray, 1997) or rainfall distribution (e.g. Lovejoy and Mandelbrot, 1985). Understanding the scales of variation within snow-depth distributions in particular will also allow more effective field-survey strategies for measuring snow-depth distributions to be designed, avoiding such problems as possible spatial autocorrelation within measured snow depths.

Given the increasing dependence on distributed modelling in studies of glacier mass balance and energy balance, evaluation of the spatial variability of these factors is important in order to improve both catchment-scale studies and wider estimates of the sensitivity of glacier mass balance to climate change.

\section{METHODOLOGY}

\section{Data collection}

These investigations relied primarily on direct measurement of glacier surface characteristics. Data were collected on midre Lovénbreen, a $6 \mathrm{~km}^{2}$ valley glacier in the Kongsfjord area of northwest Spitsbergen, Svalbard (Fig. 1), during the course of two field seasons in summer 1999 and late winter 2000.

Snow-depth measurements were made using a calibrated steel avalanche probe, at $1 \mathrm{~m}$ intervals along four longitudinal and eight transverse transects (shown in Fig. 1), and are summarized in Table 1. Transect locations were chosen randomly at a local level, but ensuring adequate coverage of the altitudinal range of the glacier given accessibility restrictions caused by the presence of two deeply incised supraglacial streams. The probe was calibrated at $1 \mathrm{~cm}$ intervals. Given the softness of the snow surface, and the possible 
Table 1. Snow-depth transect properties

\begin{tabular}{|c|c|c|c|c|c|c|}
\hline Transect & Date & $\begin{array}{c}\text { Elevation } \\
\text { ma.s.l. }\end{array}$ & Profile & $\begin{array}{c}\text { Length } \\
\mathrm{m}\end{array}$ & $\begin{array}{c}\text { Mean depth } \\
\mathrm{cm}\end{array}$ & $\begin{array}{c}\text { Std dev. } \\
\mathrm{cm}\end{array}$ \\
\hline \multicolumn{7}{|c|}{ 1. Summer 1999 data } \\
\hline L991 & 6 July 1999 & 280 & Long & 200 & 41.8 & 4.38 \\
\hline L992 & 12 July 1999 & 315 & Long & 100 & 33.2 & 3.40 \\
\hline C991 & 6 July 1999 & 280 & Cross & 200 & 41.7 & 4.04 \\
\hline C992 & 12 July 1999 & 315 & Cross & 100 & 29.8 & 3.47 \\
\hline C993 & 7 July 1999 & 380 & Cross & 100 & 85.6 & 3.45 \\
\hline Mean & - & - & - & - & 46.4 & 3.75 \\
\hline \multicolumn{7}{|c|}{ 2. Spring 2000 data } \\
\hline L001 & 8 Apr. 2000 & 105 & Long & 300 & 129.5 & 10.11 \\
\hline L002 & 11 Apr. 2000 & 325 & Long & 500 & 147.1 & 8.64 \\
\hline C001 & 8 Apr. 2000 & 105 & Cross & 300 & 77.2 & 15.73 \\
\hline C002 & 8 Apr. 2000 & 195 & Cross & 100 & 90.4 & 8.27 \\
\hline C003e & 9 Apr. 2000 & 240 & Cross & 136 & 126.7 & 16.46 \\
\hline $\mathrm{C} 003 \mathrm{w}$ & 9 Apr. 2000 & 240 & Cross & 154 & 127.1 & 8.08 \\
\hline C004e & 11 Apr. 2000 & 325 & Cross & 200 & 139.0 & 9.02 \\
\hline C004w & 11 Apr. 2000 & 325 & Cross & 300 & 135.38 & 13.43 \\
\hline C005 & 11 Apr. 2000 & 380 & Cross & 500 & 160.2 & 9.82 \\
\hline Mean & - & - & - & - & 125.8 & 11.06 \\
\hline
\end{tabular}

presence of ice lenses within the snowpack (which would prevent the measurement of the full snow depth), absolute accuracy is hard to assess. Field experience suggested that the relatively small tip $\left(\sim 0.25 \mathrm{~cm}^{2}\right)$ could penetrate many ice layers with some effort, and that the glacier surface itself also tended to "ring" through the probe. We are thus quite confident that all measurements reflect the true depth. Thus, the accuracy of the recorded depths should be $\pm 1 \mathrm{~cm}$.

Albedo was measured using a Kipp and Zonen CM7B albedometer, mounted on a camera tripod, linked to a Campbell CR10 logger. This allowed easy deployment of the instrument over a wide area of the glacier, and ensured that the instrument was parallel to the surface, rather than horizontal, which can lead to large errors in measured albedo over sloping surfaces (Mannstein, 1985). Given that the focus of this study is the small-scale variability in surface albedo, the instrument was mounted $0.5 \mathrm{~m}$ above the surface. Given the "footprint" of the instrument at this height (90\% of radiation received by the downwards-facing pyranometer received from within a $1.5 \mathrm{~m}$ radius (Schwerdtfeger, 1976)), measurements were made at $2.5 \mathrm{~m}$ intervals (the smallest practical spacing minimizing footprint "overlap") along an $1800 \mathrm{~m}$ long centre-line transect on 16 July 1999. This extended from $\sim 225$ to $\sim 375$ m a.s.l. The weather on this day was fine, with clear skies, minimizing any impact on measured albedo from changing sky conditions. Measurements were made between 1100 and $1515 \mathrm{~h}$ to avoid as far as possible the influence of high solar-zenith angles on measured albedo; solar-zenith angles during the measurement period varied between $59^{\circ}$ and $62^{\circ}$. Using the albedo correction from Lefebre and others (2003), the correction that needs to be applied is negligible, $0-0.004$, and only affects the 22 measurements made after $1500 \mathrm{~h}$. The albedometer was damaged during shipping in spring 2000, however, so albedo measurements could only be made during summer 1999.

Surface roughness was measured in two ways. Conventional microtopographic techniques (Lettau, 1969; Munro, 1990; Brock and others, 2000b), which involve measuring the distance from the glacier surface to a horizontal ranging pole or taut string, were made at 10 and $50 \mathrm{~cm}$ intervals along 2 and $10 \mathrm{~m}$ long profiles. Additionally, we used a novel technique developed in the Scott Polar Research Institute, Cambridge, U.K. (Rees, 1998), using a digital camera, in which a black back plate, $1 \mathrm{~m}$ long, is inserted vertically into the glacier surface. The photograph is then imported into an image-processing environment. The surface profile can then be derived using edge detection, and then rasterized, to allow the roughness to be calculated. This technique effectively allowed $2.5 \mathrm{~mm}$ horizontal resolution along $1 \mathrm{~m}$ long profiles. Surface roughness measurements were made at the four locations shown by $\mathrm{X}$ in Figure 1.

\section{Data analysis}

Small-scale spatial variability of the measured glacier surface properties was evaluated principally by constructing semivariograms of difference in value with spatial separation of measurements. The semivariance, $\gamma(h)$ is defined as half the squared difference in value, $x$, between measurements $i$ and $j$, separated by distance $h$, and is calculated by:

$$
\gamma(h)=\frac{1}{2|N(h)|} \sum_{N(h)}\left(x_{i}-x_{j}\right)^{2},
$$

where $N(h)$ is the number of points separated by distance $h$.

Graphs of semivariance against separation provide useful information about the spatial variability of the measured properties of the glacier surface. At a simple level, the shape of the graph indicates whether the surface has any selfsimilar properties or not, as self-similar functions show a power-law dependence of variance on separation distance (Rees, 1992). In this case, the slope $(\beta)$ of the best-fit line of the linear section of a logarithmic plot of semivariance and separation can then be used to infer the fractal dimension $(D)$ of the data, as $\beta=4-2 D$ (Burrough, 1986). This is effectively a measure of the scale-dependent roughness of the surface, with a higher fractal dimension indicating a rougher surface.

Typically, natural phenomena do not show fractal behaviour at all spatial scales. Normally, fractal behaviour is observed at short separations, with increasing variance as separation increases. This normally reaches some maximum level at a given separation, after which it does not increase further. This maximum variance is typically called the "sill". The sill effectively marks the transition to uncorrelated behaviour in the series, and the separation distance at which this occurs is thus the maximum distance within which spatially autocorrelated measurements will occur (often called the "range").

The definition of the sill and the range are therefore important aspects in analyzing semivariograms. A variety of methods are available; some authors have simply used visual estimation (e.g. Shook and Gray, 1996), but more commonly some form of mathematical relationship is fitted to the data using a variety of optimization methods (e.g. Kitanidis, 1997).

\section{RESULTS}

\section{Snow depth}

Over 2500 individual snow-depth measurements were made during the course of the two field seasons. Typical snowdepth transects are shown in Figure 2. Analysis of the 


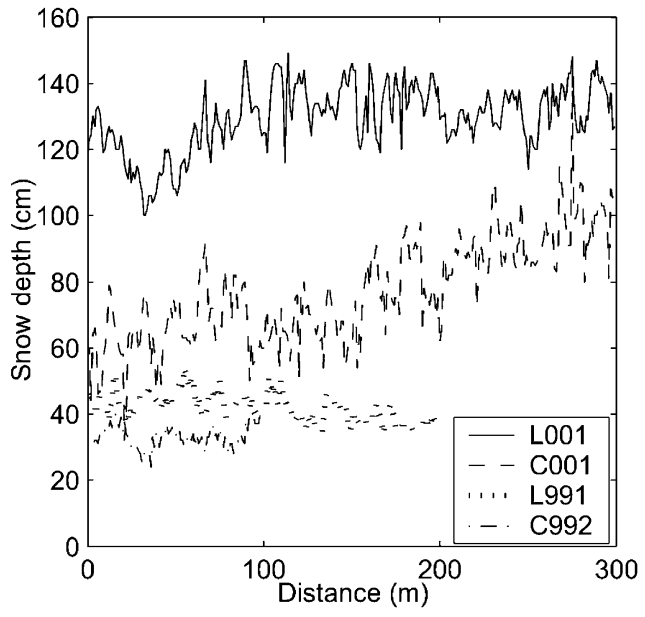

Fig. 2. Examples of typical snow-depth transects. For transect locations, see Table 1.

snow-depth transects showed considerable variation of depth both within and between transects (Table 1). However, the differences between the summer and spring data were much greater than the differences within these classes (Table 2); the depth and the standard deviation of snow depth was, on average, three times greater in spring than in summer.

Using all data, the standard deviation of depth increases with depth $\left(R^{2}=37.0 \% ; F=7.04\right.$ (significant at $95 \%$ confidence interval)). However, for the summer data, no significant relationship exists, largely due to the low variance of transect T993, the highest measured transect, with the greatest snow depth. For the spring data, the standard deviation seems to decrease with increasing depth, although the relationship is not significant $\left(R^{2}=11 \% ; F=0.87\right.$ ).

The mean summer and mean spring semivariograms also show clear differences between spring and summer snow-depth distributions (Fig. 3). Although the semivariograms for both seasons show a similar overall shape, with the variance increasing at short separations before reaching a reasonably flat sill of constant variance, the range is different, at around 10-20 m separations in summer, and around 35-45 $\mathrm{m}$ separations in spring. The sill variance is also higher in spring than in summer.

The mean semivariograms were modelled using an exponential relationship of the form:

$$
\gamma=a\left[1-\exp \left(-h / h_{0}\right)\right]
$$

where $a$ is an adjustable parameter and $h_{0}$ is the (adjustable) correlation length. This gave best-fitting parameter values of $a=12.1 \mathrm{~cm}^{2}$ in summer and $147 \mathrm{~cm}^{2}$ in spring, and $h_{0}=2.71 \mathrm{~m}$ in summer and $16.66 \mathrm{~m}$ in spring, with $R^{2}$

Table 2. Inferential statistics for transect properties

\begin{tabular}{lccc}
\hline Test & Statistic & Value & $\begin{array}{c}\text { Significance } \\
\%\end{array}$ \\
\hline $\begin{array}{l}\text { Difference between all spring and all } \\
\quad \text { summer data }\end{array}$ & $t$ & 100.7 & 99.999 \\
$\begin{array}{l}\text { Difference between all spring and all } \quad \text { summer data } \\
\begin{array}{l}\text { Difference within summer data } \\
\text { Difference within spring data }\end{array}\end{array}$ & $F$ & 6221.3 & 99.999 \\
& $F$ & 1389.2 & 99.999 \\
\hline
\end{tabular}

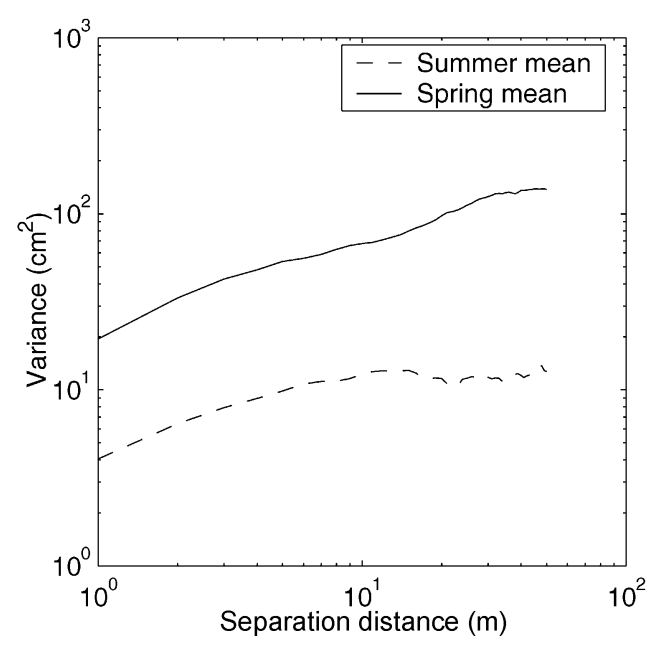

\section{Fig. 3. Mean semivariograms of snow-depth distribution for} spring and summer.

for the fitted relationships of $83.6 \%$ in summer and $96.1 \%$ in spring.

These results indicate that snow-depth distributions show fractal properties at short spatial separations, but that the distribution becomes effectively random as separation increases. This has been observed in shallow continental snow covers (Shook and Gray, 1996), but not, as far as the authors are aware, on the surfaces of glaciers. The spatial separation at which the transition to a random distribution occurs, however, is longer in early spring than in summer.

\section{Albedo}

Field observations suggest that three main surface facies types can be identified on midre Lovénbreen in summer: (i) bare glacier ice at lower elevations; (ii) a mixed zone, consisting of bare ice, thin unsaturated snow and saturated snow at intermediate elevations, marking the transition from bare ice to continuous snow cover; and (iii) unbroken snow cover overlying ice at high elevations. As discussed above, most energy-balance studies include "ice" and "snow" facies, and use differing roughness and albedo values or parameterizations (e.g. Oerlemans, 1993; Arnold and others, 1996; Brock and others, 2000b). The "mixed" central zone is typically missing from such studies, however, which show a sharp transition from "snow" to "ice". Some studies include a "firn" surface type (e.g. Hock and Noetzli, 1997), but this is not strictly analogous; firn only occurs at high elevations, towards the end of the melt season, when the overlying current-year snow has melted. In the ablation zone, firn is, by definition, absent. The mixed zone observed on midre Lovénbreen, however, migrates up-glacier with the transient snowline.

The longitudinal (centre-line) albedo transect from midre Lovénbreen is shown in Figure 4. These data broadly support the presence of these three surface facies. At distances up to around $1150 \mathrm{~m}$ along the transect, we observed a surface consisting of bare glacier ice, with increasing albedo with elevation and a large degree of spatial variability. After this, there is a narrow zone with a rapid increase in albedo, and a large degree of variability, marking the mixed zone. At around $1250 \mathrm{~m}$ distance, continuous snow cover occurs, which again shows an upward trend in albedo with elevation, although with somewhat lower spatial variability. 


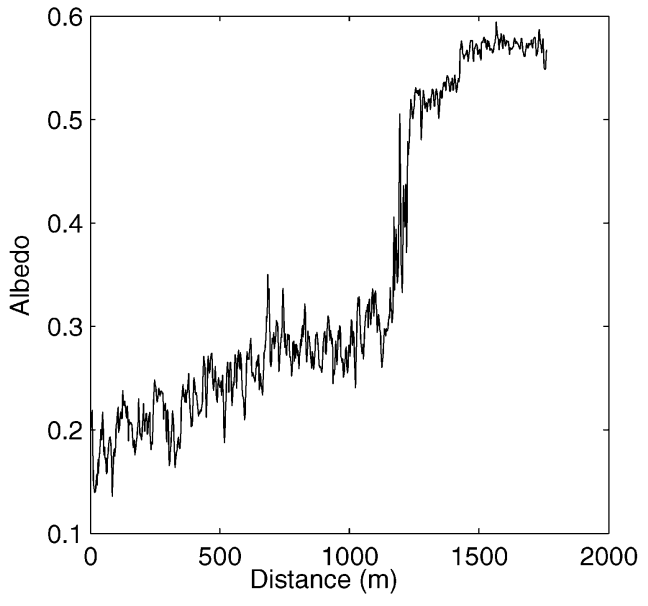

Fig. 4. Centre-line albedo profile, 16 July 1999. For location, see text.

The semivariograms for each of the three surface facies on midre Lovénbreen are shown in Figure 5. The semivariogram for ice suggests fractal behaviour at small scales (increasing variance), before again reaching a constant level of variance. The semivariogram was again modelled using an exponential relationship. Best-fit values for ice are $a=0.0003$ and $h_{0}=8.30 \mathrm{~m}, R^{2}=99.4 \%$. At large separations (over $\sim 150 \mathrm{~m}$ ), there is some indication that albedo variance increases again; this is quite close to the maximum distance at which reliable semivariances can be calculated (around half the transect length), and so needs to be regarded with caution.

The semivariogram for snow is rather different. For spatial separations of up to $50 \mathrm{~m}$, snow albedo shows similar behaviour to ice: an increase in variance at small separations, before the variance levels off at around $20 \mathrm{~m}$ separation. Using an exponential model for this section of the semivariogram, best-fit parameter values are $a=0.000094$ and $h_{0}=4.37 \mathrm{~m}, R^{2}=69.0 \%$. This correlation length is similar to that for the mean semivariogram of summer snow-depth measurements $(2.71 \mathrm{~m})$. If the variances for the two longitudinal summer transects (L991 and L992) are analyzed independently, however, for separations up to $50 \mathrm{~m}$, the calculated correlation lengths for snow depth are $4.51 \mathrm{~m}$ for L991 and $3.73 \mathrm{~m}$ for L992, in close agreement with the albedo length. At separations larger than $60-70 \mathrm{~m}$, the variance in snow albedo begins to increase again, with a fractal dimension of 1.41. Given that this increase in variance occurs at much shorter separations than for ice, it can be regarded as more reliable than the increase identified for ice above. Variances are lower for snow than for ice at short separations, but rise to similar values for ice at higher separations. Correcting for the impact of solar zenith angles had no effect on these results.

The semivariogram for the mixed zone is different again. The variance increases very quickly as separation increases, and reaches no obvious sill. The possible spatial separations are obviously limited in this case by the limited spatial extent of around $100 \mathrm{~m}$ of the transition zone. The rapid increase in variance leads to a higher fractal dimension of 1.69. The overall albedo semivariogram seems to be dominated by the snow albedo variance, exhibiting different scaling behaviour at different separations, with fractal characteristics at small scales, a sill at intermediate scales and fractal behaviour at larger scales.

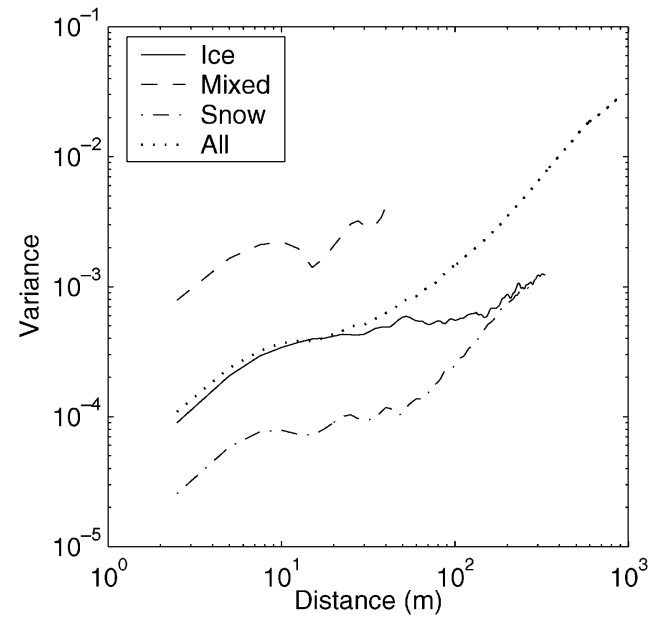

Fig. 5. Albedo semivariograms for the three surface facies discussed in the text, and for the whole transect. "Ice" = bare glacier ice; "Mixed" = central zone of mixed surfaces; "Snow" = zone of continuous snow cover; "All" = all data, ignoring surface type (see text).

\section{Surface roughness}

Average semivariograms for the microscale surface roughness measurements from analysis of digital photographs (covering scales from $2 \mathrm{~mm}$ to $1 \mathrm{~m}$ ) and conventional transects $(0.1-10 \mathrm{~m})$ for summer 1999 are shown in Figure 6. The two techniques are consistent, with all three surface types showing fractal behaviour over the whole range of measured scales. Although the fractal dimensions from the two techniques are similar, there is a change in the calculated variance between the two techniques. This may relate to the accuracy of the measurements. The photographic technique can resolve height differences to $\pm 2 \mathrm{~mm}$ (the effective pixel size in the images); the pole technique is less accurate. Measuring a soft snow surface in particular is difficult; the pole tends to sink into the snow, and the tape measure can also be unintentionally pushed into the snow. Overall accuracy of this technique is therefore likely to be $\pm 10 \mathrm{~mm}$ for snow, $\pm 5 \mathrm{~mm}$ for ice surfaces.

Fractal dimensions calculated using photographic data are 1.73 for ice, 1.62 for the mixed facies and 1.51 for snow. Ice shows a much higher semivariance than the mixed zone at all spatial separations, and than snow at small separations; the smaller fractal dimension of the snow surface results in similar semivariances at larger separations, however. The conventional microtopographic technique shows consistent fractal dimensions of 1.76 for ice and 1.65 for the mixed surfaces; for snow, however, the observed decrease in semivariance at separations of $0.5-1.0 \mathrm{~m}$ leads to a fractal dimension of 1.91 .

The early-spring semivariograms at the four study locations are shown in Figure 7. There is some indication for decreasing fractal dimension with altitude; values range from $D=1.78$ at $130 \mathrm{~m}$ to 1.59 at $385 \mathrm{~m}$. The semivariances at $\mathrm{mm}$ to $\mathrm{cm}$ scales are similar, but the smaller fractal dimension leads to larger semivariance as scales approach $0.5 \mathrm{~m}$. The conventional microtopographic measurements give less consistent results. Fractal dimensions are generally lower, ranging from 1.29 to 1.56 , with no altitude trend.

Other roughness parameters generated from the surface roughness data were the rms height variation $\sigma$, and the aerodynamic roughness length $z_{0}\left(=\sigma^{2} f\right.$, where $f$ is the 


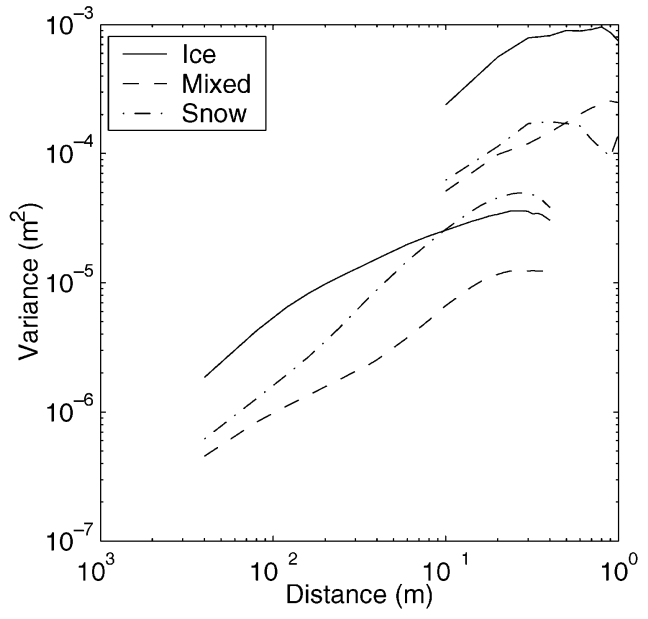

Fig. 6. Surface roughness semivariograms for the three surface facies for summer 1999. Key is explained in Figure 5 caption.

frequency of zero-crossings in a de-trended height profile), important in energy-balance models (e.g. Munro, 1990; Brock and others, 2000b). These are summarized in Table 3 for the different measurement periods, glacier surface facies and measurement techniques.

During spring, the surfaces were found to be very smooth, with mean $z_{0}$ values from both techniques of $\sim 0.04 \mathrm{~mm}$. These values are in broad agreement with other studies of high-latitude non-melting snow surfaces (e.g. King and Anderson, 1994). Roughness was somewhat higher at the lowest measurement location.

For the summer data, ice was rougher than both snow and the mixed surface. However, the mixed surface was found to be smoother than snow. Snow in this zone was typically saturated; it may be that flow of this saturated snow into lower areas effectively smoothed the surface. Again, both measurement techniques produced similar results, although for all three surface types the conventional technique produced smaller $z_{0}$ values. This may suggest that the calculated aerodynamic roughness length is dependent on the scale of measurement. This is an important result that requires further investigation, due to the control exerted by the surface roughness on turbulent heat exchange at the glacier surface.

\section{DISCUSSION}

Our observations have shown that glacier surface characteristics exhibit self-similar properties over a wide range of spatial scales, from $\mathrm{mm}$ to tens of metres. Snow-depth distributions and surface albedo behave similarly; both show increasing variance (indicating self-similar behaviour) at small spatial scales, before reaching some maximum variance at larger separations (Figs 3 and 5). There is some indication that at larger scales $(>100 \mathrm{~m})$, albedo again begins to behave in a self-similar manner, with increasing variance as spatial separation increases.

At a practical level, these data allow the sampling strategy needed to characterize the spatial variability of these variables to be determined. In order to minimize any problems of spatial autocorrelation in nearby measurements, minimum measurement separation distances suggested by the semivariograms should be used. For the exponential model used here, the range is approximately

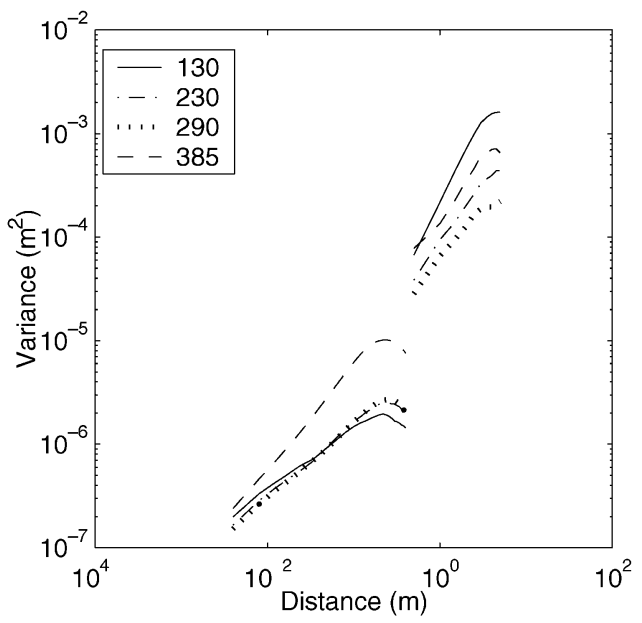

Fig. 7. Surface roughness semivariograms for spring 2000. Key is elevation of measurements in m a.s.l.

$3 h_{0}$ (Kitanidis, 1997); thus, in order to avoid spatial autocorrelation in snow-depth and albedo measurements, sample points should be separated by distances of $\sim 8 \mathrm{~m}$ in summer, but up to $\sim 50 \mathrm{~m}$ in spring. However, this distance cannot be determined except by empirical observation; the differences between the spring and summer data described here suggest that for any given study, an initial pilot survey may need to be carried out and analyzed before the main survey takes place, in order to optimize the sampling strategy for the particular glacier and/or season under investigation.

The spatial distribution of winter snow depth over a glacier reflects the patterns of snow accumulation, and its spatial variability. However, the topography of the glacier surface itself must also play a role. Here, we are referring to both the large-scale "map" topography, at scales of tens to hundreds of metres, but also the small-scale topography (perhaps better described as "roughness"), at scales of $\mathrm{mm}$ to metres. Intuitively, topographic hollows (at any scale) will tend to fill first and, hence, contain deeper snow than topographic highs. Given that the ice topography beneath a snow cover presumably remains unchanged (at least until the snow has melted, exposing the ice to ablation), the change in the spatial characteristics of snow depth that we observed from early spring (before any melt) through to summer must therefore reflect a change in the factors controlling snow depth, i.e. they reflect the influence of ablation, rather than accumulation. The observed change in spatial characteristics must therefore indicate that the small-scale spatial variability of ablation is different from

\section{Table 3. Surface roughness parameters}

\begin{tabular}{lcccc}
\hline $\begin{array}{l}\text { Measurement } \\
\text { period }\end{array}$ & Surface type & Technique & $\begin{array}{c}\text { Mean } \sigma \\
\mathrm{mm}\end{array}$ & $\begin{array}{c}\text { Mean } z_{0} \\
\mathrm{~mm}\end{array}$ \\
\hline Spring 2000 & Snow & Camera & 2.1 & 0.043 \\
Spring 2000 & Snow & Pole & 9.0 & 0.048 \\
Summer 1999 & Snow & Camera & 6.9 & 0.34 \\
Summer 1999 & Snow & Pole & 11.2 & 0.22 \\
Summer 1999 & Mixed & Camera & 5.8 & 0.25 \\
Summer 1999 & Mixed & Pole & 12.1 & 0.13 \\
Summer 1999 & Ice & Camera & 7.6 & 0.66 \\
Summer 1999 & Ice & Pole & 29.5 & 0.62 \\
& & & & \\
\hline
\end{tabular}

Note: "Mixed" denotes the transition zone between continuous ice cover and continuous snow cover (see text). 
that of accumulation. In many ways, this is only to be expected, given the very different physical processes involved, but observing this change is interesting, and may suggest that the spatial resolution of accumulation and ablation models need not be the same.

The observed spatial characteristics of albedo were different for bare ice surfaces, continuous snow cover and for the "mixed" zone separating these two. As discussed earlier, surface albedo is one of the key controls on the spatial pattern of ablation, but physically based determination of glacier-wide albedo remains very difficult. Our results suggest that the spatial variability of albedo is different between ice and snow surfaces, in terms of both the absolute variability and the scale of spatial autocorrelation. Ice albedo is both more variable (by a factor of $\sim 3$ ), and shows spatial autocorrelation over larger areas than snow (by a factor of $\sim 2$ ).

In spite of the recent findings of Brock and others (2000a), in which the most effective parameterization for albedo used accumulated temperature, rather than snow depth, the similarity in correlation lengths for the variation of summer snow depth and albedo in this study suggests that snow depth remains an important determinant of glacierwide albedo patterns. Both accumulated temperature and snow depth will be proportional to snowmelt (once the melt season is underway), and so both will have some control over snow metamorphism, and the increasing concentration of impurities within a snowpack as the melt season progresses, which are physically responsible for the observed changes in snow albedo (e.g. Wiscombe and Warren, 1980). It may be that the parameters highlighted by Brock and others can better parameterize the large-scale evolution of albedo over glacierized surfaces during a melt season, but that the small-scale variations in snow depth highlighted in this study contribute to the smaller-scale spatial variation in albedo over the glacier surface at any given time. Given the likely positive feedback between snowmelt (and hence snow depth) and reducing albedo during the course of a melt season, this link may be responsible for the changing spatial variability of snow depth discussed above, and ultimately the development of the patchy transition zone between bare ice at low elevations and continuous snow cover at higher elevations.

The surface roughness of ice and snow surfaces also shows self-similar behaviour over the range of spatial scales investigated here. Unlike snow depth and albedo, however, we found no evidence of a sill in the semivariograms; variance continued to increase with spatial separation, although the fractal dimension seemed to decrease at larger separations. Ice and snow surfaces showed different surface roughness characteristics, and the "mixed" zone at the transient snowline discussed above was different again, showing very smooth surfaces.

Determination of the surface roughness of glaciers, and its spatial variability, is important as it impacts the turbulent heat exchange between the ice and the atmosphere. Despite their theoretical inferiority, bulk methods of determining turbulent fluxes have often been more successful than profile methods when applied to glacierized surfaces (e.g. Hay and Fitzharris, 1988; Denby and Greuell, 2000). Given this, and their simpler data requirements, such techniques are likely to remain important into the future. Their use, however, relies on knowledge of the roughness lengths of the glacier surface. These can be determined from atmospheric measurements, but again this is both theoretically difficult, given the atmospheric conditions which prevail over glacier surfaces, such as strong temperature inversions and katabatic flows (Denby and Greuell, 2000), and logistically challenging, due to the need to maintain a complex instrument suite in a hostile environment. Thus, direct measurement of the surface roughness elements, coupled with an assumption about their relationship with aerodynamic roughness, seems likely to remain an important technique. This study highlights a previously unrecognized problem, however: the scale over which such measurements are made has some influence over the calculated roughness length. If a surface transect can be thought of as a fractal Brownian motion with fractal dimension $D$, we would expect $z_{0}$ to scale with $X^{(3-2 D)}$, where $X$ is the transect length. Thus, if the fractal dimension is $\sim 1.5, z_{0}$ should be independent of the transect length. For fractal dimensions of $<1.5$, $z_{0}$ will increase with transect length, and for $D>1.5, z_{0}$ will decrease. This seems to be borne out by our results: summer fractal dimensions for ice and the mixed surface are both $>1.5$, as is $D$ for snow from the conventional technique; in all cases, $z_{0}$ values are lower for the longer conventional transects. The spring results are less consistent, however, as the fractal dimension varies more with the scale of measurement.

This would indicate that further investigation is needed, in order to ensure that optimal measurement techniques are used. It may be that the use of fractal dimensions of surface profiles can also be related usefully to aerodynamic roughness, and may provide an alternative surface roughness index for use in turbulent heat exchange studies. However, it is perhaps fortunate that as Denby and Greuell (2000) point out, an order-of-magnitude error in $z_{0}$ will typically only lead to a $25 \%$ error in the surface heat fluxes.

\section{CONCLUSIONS}

This study has shown that spatial distributions of snow depth, albedo and surface roughness on a glacier all exhibit self-similar or fractal behaviour at a variety of spatial scales. Snow depth and albedo show self-similar behaviour at small scales (up to approximately $50 \mathrm{~m}$ ), after which the variance reaches a constant value. The scale at which this occurs varies from early spring to summer. There is some evidence that the albedo of snow, and possibly ice, also shows self-similar behaviour at larger scales (over $\sim 75-100 \mathrm{~m}$ ). Surface roughness showed self-similar behaviour at all the scales measured in this study ( $\mathrm{mm}$ to tens of metres).

This behaviour has implications for the sampling strategies which should be used to characterize glacier-wide patterns of snow depth, albedo and surface roughness in future studies, as it indicates that spatial autocorrelation can exist at quite considerable distances (up to $\sim 50 \mathrm{~m}$ ) over glacier surfaces.

To avoid these problems, we suggest that characterization of the snow-depth distribution over a glacier should be a two-phase process. Pilot studies of snow depth should be carried out, consisting of spatially intensive (every $1-2 \mathrm{~m}$ ) measurements of depth along transects at least $100 \mathrm{~m}$ long in order to identify the range at which the semivariance becomes constant (and whether this distance changes in different areas of the glacier, perhaps with elevation). Depending on the size of the glacier, these transects could be separated by $1-2 \mathrm{~km}$, although the findings of the initial 
measurements could suggest more transects would be beneficial if the range was found to be very variable. These data should then be used to indicate minimum separation distances between more widespread measurements over the glacier surface to allow spatial interpolation of the measured values into the "digital snow-depth models" used in energy- and mass-balance studies.

Given the complexity of the physical determinants of glacier surface characteristics, it seems likely that empirical models of snow depth, albedo and roughness are likely to be used in mass- and energy-balance studies for some considerable time. This research has shown that the generally smooth spatial variation of these properties in such models is likely to be inadequate, as such models cannot produce the degree of spatial variability found in this study.

The next stage of this research is to use the derived semivariograms to incorporate the small-scale variability in surface characteristics into the tens-of-metres scale digital models of snow depth, albedo and roughness used in distributed energy-balance studies, evaluating the effect of such variability at both sub-pixel and between-pixel scales on the season-long energy balance and the spatial patterns of melt over glacier surfaces.

\section{ACKNOWLEDGEMENTS}

This work was supported by the U.K. Natural Environment Research Council (NERC) grant GR8/04431, the B. B. Roberts Fund of the Scott Polar Research Institute, St John's College, Cambridge, and the University of Cambridge. We also thank the manager, N. Cox, and his deputy, B. Newham, of the NERG Arctic research station, Ny Ålesund, for their invaluable logistic assistance. D. Rippin, A. Hodson and various undergraduate students also provided valuable assistance in the field. J. Dowdeswell provided valuable comments on an earlier draft of the manuscript, and the two reviewers, particularly B. Brock, also made valuable comments. The Scientific Editor was M. van den Broeke.

\section{REFERENCES}

Arnold, N. S., I. C. Willis, M. J. Sharp, K. S. Richards and W. J. Lawson. 1996. A distributed surface energy-balance model for a small valley glacier. I. Development and testing for Haut Glacier d'Arolla, Valais, Switzerland. 7. Glaciol., 42(140), 77-89.

Arnold, N., K. Richards, I. Willis and M. Sharp. 1998. Initial results from a distributed, physically based model of glacier hydrology. Hydrol. Processes, 12, 191-219.

Braithwaite, R. J. and O. B. Olesen. 1990. A simple energy-balance model to calculate ice ablation at the margin of the Greenland ice sheet. $\mathcal{F}$. Glaciol., 36(123), 222-228.

Braithwaite, R. J. and Y. Zhang. 2000. Sensitivity of mass balance of five Swiss glaciers to temperature changes assessed by tuning a degree-day model. F. Glaciol., 46(152), 7-14.

Brock, B.W., I. C. Willis and M. J. Sharp. 2000a. Measurement and parameterization of albedo variations at Haut Glacier d'Arolla, Switzerland. f. Glaciol., 46(155), 675-688.
Brock, B.W., I. C. Willis, M. J. Sharp and N. S. Arnold. 2000b. Modelling seasonal and spatial variations in the surface energy balance of Haut Glacier d'Arolla, Switzerland. Ann. Glaciol., 31, 53-62.

Burrough, P. A. 1986. Principles of geographical information systems for land resources assessment. Oxford, Clarendon Press. (Monographs on Soils and Resources Survey 12.)

Denby, B. and W. Greuell. 2000. The use of bulk and profile methods for determining surface heat fluxes in the presence of glacier winds. $\mathcal{F}$. Glaciol., 46(154), 445-452.

Escher-Vetter, H. 1985. Energy balance calculations for the ablation period 1982 at Vernagtferner, Oetztal Alps. Ann. Glaciol., 6, 158-160.

Hay, J. E. and B. B. Fitzharris. 1988. A comparison of the energy-balance and bulk-aerodynamic approaches for estimating glacier melt. $\mathcal{f}$. Glaciol., 34(117), 145-153.

Hock, R. and B. Holmgren. 1996. Some aspects of energy balance and ablation of Storglaciären, northern Sweden. Geogr. Ann., 78A(2-3), 121-131.

Hock, R. and C. Noetzli. 1997. Areal melt and discharge modelling of Storglaciären, Sweden. Ann. Glaciol., 24, 211-216.

King, J. C. and P. S. Anderson. 1994. Heat and water vapour fluxes and scalar roughness lengths over an Antarctic ice shelf. Boundary-Layer Meteorol., 69(1-2), 101-121.

Kitanidis, P. K. 1997. Introduction to geostatistics. Cambridge, Cambridge University Press.

Knap, W. H., B. W. Brock, J. Oerlemans and I. C. Willis. 1999. Comparison of Landsat TM-derived and ground-based albedos of Haut Glacier d'Arolla, Switzerland. Int. 7. Remote Sensing, 20(17), 3293-3310.

Laumann, T. and N. Reeh. 1993. Sensitivity to climate change of the mass balance of glaciers in southern Norway. 7. Glaciol., 39(133), 656-665.

Lefebre, F., H. Gallée, J. P. van Ypersele and W. Greuell. 2003. Modeling of snow and ice melt at ETH camp (West Greenland): a study of surface albedo. 7. Geophys. Res., 108 (D8), Art. No. 4231.

Lettau, H. 1969. Note on aerodynamic roughness-parameter estimation on the basis of roughness element description. F. Appl. Meteorol., 8(5), 828832.

Lovejoy, S. and B. B. Mandelbrot. 1985. Fractal properties of rain, and a fractal model. Tellus, 37(3), 209-232.

Mannstein, H. 1985. The interpretation of albedo measurements on a snow covered slope. Arch. Meteorol. Geophys. Bioklimatol., Ser. B, 36(1), 73-81.

Munro, D.S. 1990. Comparison of melt energy computations and ablatometer measurements on melting ice and snow. Arct. Alp. Res., 22(2), $153-162$.

Munro, D. S. and G. J. Young. 1982. An operational net shortwave radiation model for glacier basins. Water Resour. Res., 18(2), 220-230.

Oerlemans, J. 1993. A model for the surface balance of ice masses: Part 1. Alpine glaciers. Z. Gletscherkd. Glazialgeol., 27-28, [1991-1992], 63-83.

Rees, W. G. 1992. Measurement of the fractal dimension of ice-sheet surfaces using Landsat data. Int. F. Remote Sensing, 13(4), 663-671.

Rees, W. G. 1998. Correspondence. A rapid method for measuring snow surface profiles. F. Glaciol., 44(148), 674-675.

Schwerdtfeger, P. 1976. Physical principles of micrometeorological measurements. Amsterdam, Elsevier. (Developments in Atmospheric Science 6.)

Shook, K. and D. M. Gray. 1996. Small-scale spatial structure of shallow snowcovers. Hydrol. Processes, 10, 1283-1292.

Shook, K. and D. M. Gray. 1997. Synthesizing shallow seasonal snowcovers. Water Resour. Res., 33(3), 419-424.

Van de Wal, R. S. W., J. Oerlemans and J. C. van der Hage. 1992. A study of ablation variations on the tongue of Hintereisferner, Austrian Alps. $\mathcal{F}$. Glaciol., 38(130), 319-324.

Willis, I. C., M. J. Sharp and K. S. Richards. 1993. Studies of the water balance of Midtdalsbreen, Hardangerjökulen, Norway: 1. The calculation of surface water inputs from basic meteorological data. Z. Gletscherkd. Glazialgeol., 27-28, [1991-1992], 97-115.

Willis, I., N. Arnold and B. Brock. 2002. Effect of snowpack removal on energy balance, melt and runoff in a small supraglacial catchment. Hydrol. Processes, 16, 2721-2749.

Wiscombe, W. J. and S. G. Warren. 1980. A model for the spectral albedo of snow. I. Pure snow. F. Atmos. Sci., 37(12), 2712-2733. 